$$
\text { CONF- } 960 \% 172-1
$$

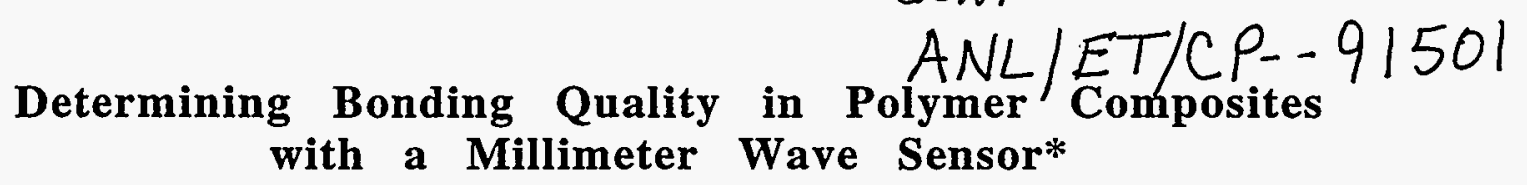

by

RECENED

I:n!" 12 1996

S. Bakhtiari, N. Gopalsami, and A. C. Raptis

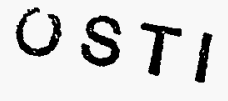

Energy Technology Division

Argonne National Laboratory

Argonne, Illinois 60439

\begin{abstract}
The submitted manuscript has been authored by a contractor of the U.S. Government under contract No. W-31-109-ENG-38. Accordingly, the U.S. Government retains a nonexclusive, royalty-free license to publish or reproduce the published form of this contribution, or allow others to do so, for U.S. Government purposes.
\end{abstract}

DISTRIBUTION OF THIS DOCUMENT IS UHLMMTEO

Submitted to Review of Progress in Quantitative Nondestructive Evaluation, Vol. 16

*Work supported by the Office of Energy Research, U. S. Department of Energy, under Contract W-31-109-ENG-38 


\section{DISCLAIMER}

This report was prepared as an account of work sponsored by an agency of the United States Government. Neither the United States Government nor any agency thereof, nor any of their employees, makes any warranty, express or implied, or assumes any legal liability or responsibility for the accuracy, completeness, or usefulness of any information, apparatus, product, or process disclosed, or represents that its use would not infringe privately owned rights. Reference herein to any specific commercial product, process, or service by trade name, trademark, manufacturer, or otherwise does not necessarily constitute or imply its endorsement, recommendation, or favoring by the United States Government or any agency thereof. The views and opinions of authors expressed herein do not necessarily state or reflect those of the United States Government or any agency thereof. 


\section{DISCLAIMER}

Portions of this document may be illegible in electronic image products. Images are produced from the best available original document. 


\title{
DETERMINING BONDING QUALITY IN POLYMER COMPOSITES WITH A
}

\section{MILLIMETER WAVE SENSOR}

\author{
S. Bakhtiari, N. Gopalsami, and A. C. Raptis \\ SI\&NDE Section, Energy Technology Division \\ Argonne National Laboratory \\ 9700 S. Cass Ave.
}

Argonne, IL 60439

\section{INTRODUCTION}

Microwave nondestructive testing (NDT) techniques offer alternative solutions to other conventional NDT methods. Microwave/millimeter wave (determined roughly to cover 0.3 to $300 \mathrm{GHz}$ ) techniques are particularly useful for examination of dielectric composite materials that their low dielectric losses provide good depth of penetration of electromagnetic radiation in this band [1-5]. Limitations associated with conventional NDT techniques such as high frequency ultrasonic testing (UT), namely, large variations in elastic properties of low density composite materials cause interpretation of complex UT signals difficult. Further, criticality of coupling of transducer to the sample surface limits the use of such techniques for on-line applications. High frequency microwave (millimeter waves, 30-300 GHz) systems, in compare to their low frequency counterparts offer higher resolution and sensitivity to variations in dielectric properties of low-loss composites. Further, higher frequencies render utilization of more compact systems which are often important for practical applications.

A millimeter wave sensor is described in this work which can be utilized for noncontact NDT of a wide range of thin-sheet dielectric composite materials either as a laboratory-based instrument or for on-line quality control applications. Experimental results are presented on noncontact measurement of bonding quality in polyethylene/ carbon composite samples. The w-band monostatic sensor operates based on measurement of the reflection properties of the material under test, which are then used to determine the volumetric uniformity of the joint area. Preliminary experimental results indicate the potential for the use of this sensor in fabrication process control of low-loss dielectric composite materials

\section{MEASUREMENT SETUP}

Figure 1(a) shows a $90^{\circ}$ section of a typical sample geometry used to carry out the measurements. Optically opaque composite specimens were high density polyethylene/ carbon (HDPE) tubes. At w-band such low-loss $\left(\tan \delta \propto 10^{-4}\right)$ dielectric materials with 
(permittivity $\dot{\varepsilon}_{r} \approx 2.3$ ) provide small attenuation and effectively a large depth of penetration [6]. These values also matched reasonably well with numerical models [2]. The samples used in this work had nominal wall thickness of $T=11.15 \mathrm{~mm}$ and the width of the joint region (not visible on the sample surface), $w$, varied depending on the quality of the fused section. In practice butt-fusion is achieved by heating and pressing together two sections of HDPE tubing sections. The direction and level of mechanical pressure inserted during the process often are the key factors that determine the quality of a joint. The process may also produce subsurface voids which can result in an unacceptable bond quality.

Figure 2 depicts the block diagram of the laboratory-based monostatic sensor used to carry out the measurements. A continuous wave signal at $94 \mathrm{GHz}$ from a Gunn diode oscillator (GDO) is divided into transmitted and local oscillator (LO) signals via a power divider (PD). The reflected radiation which contains information about volumetric . properties of the test sample is mixed with LO signal through the quadrature mixer (QIFM) that provides simultaneous amplitude and phase information. Up on amplification and filtering, the analog output signal is digitized with a PC-based D/A board. The computer also controls the translation stage for scanning of the sample.

\section{EXPERIMENTAL RESULTS}

To initially examine the resolution and sensitivity of the sensor, measurements were carried out on a tube specimen with artificial voids (drilled holes approximately $3.5 \mathrm{~mm}$ in diameter). The geometry of the sample is shown in Figure 1(b). Figure 3(a) and (b) show $\mathrm{C}$-scan normalized amplitude and phase images of the sample, respectively. Also shown below each image are two representative line scans of the data to indicate continuity and uniformity of the signal at different positions in the image. These line plots represent different positions around the pipe's circumference. Both amplitude and phase information show the presence of the two subsurface defects. The relatively large (with respect to the operating wavelength) diameter of the drilled hole gives rise to smaller secondary peak on the amplitude plots of Figure 3(a) along the scan direction.

Next an acceptable joint was examined both in reflection and through-transmission mode. For the latter setup, the system was modified with the transmitter and receiver placed on opposite sides of the test specimen. Figure 4(a) shows the measurement results for the through-transmission configuration. The line scans at two different $y$-axis locations show the uniformity of the joint area with a signal well above the base-line variations. Measurement of a different acceptable joint is shown in Figure 4(b) using the monostatic sensor i.e. reflection mode). Once again, the linear plots of the signal amplitude at different y-axis positions show an acceptable uniformity of the test specimen. 
Figures 5(a) and (b) show the measurements carried out on two unacceptable fused joints. The rejection criteria for the millimeter wave signal was based on continuity and amplitude thresholding of the signal. In both figures the $\mathrm{C}$-scan images as well as linear amplitude plots clearly indicate nonuniformity of the measured reflection at different positions along $y$-axis. Figure 5(a) shows variation of the normalized amplitude over a wide area around the defect as well as the baseline. Figure 5(b) on the other hand indicates discontinuity at different $y$-axis locations which can also be seen from the linear plots of the signal amplitude.

\section{CONCLUSION}

A w-band millimeter-wave sensor was implemented for examination of joint quality in HDPE composite tube samples. Both reflection and through transmission imaging results were presented that indicate the applicability of the system for NDT of low-loss composites (e.g. bond quality, density variation, etc.). A bench-top prototype has been assembled and tested. With minimal hardware/software modifications the system can be implemented for different on-line quality control applications.

\section{ACKNOWLEDGMENTS}

This work was supported by the U. S. Department of Energy, Office of Energy Research, under Contract w-31-109-Eng-38. The authors would also like to thank and S. Tujague of Brooks Marketing, Inc., and K. Paxton of Industrial-Utility Sales Co., Inc., for providing the samples.

\section{REFERENCES}

1. A. J. Bahr, "Nondestructive Evaluation of Ceramics," IEEE Transactions on Microwave Theory and Techniques, Vol. MTT-26, 1978, pp 676-683.

2. S. Bakhtiari, N. Gopalsami, A. C. Raptis, and M. J. Lepper, "High resolution Millimeter-Wave Imaging System for Defect Characterization in Dielectric Slabs," Proceedings of SPIE, vol. 2275, Advanced Microwave and Millimeter-Wave Detectors, San Diego, CA, 25-26 July 1994, pp. 27-33.

3. M. T. Lusk, K. Radhakrishnan, H. C. Han, and E. S. Mansueto, "Noncontact Thickness Measurement of Dielectric Coatings Using Millimeter Waves," Proceedings of SPIE, vol. 2275, Advanced Microwave and Millimeter-Wave Detectors, San Diego, CA, 25-26 July 1994, pp. 79-88.

4. E. S. Mansueto., and H. C. Han, "Noncontact Thickness Measurement of Dielectric Coatings Using Millimeter Waves," Proceedings of SPIE, vol. 2275, Advanced Microwave and Millimeter-Wave Detectors, San Diego, CA, 25-26 July 1994, pp. 7988.

5. D. W. Radford, S. I. Ganchev, N. Qaddoumi, G. Beauregard, and R. Zoughi, "Millimeter-Wave Nondestructive Evaluation of Glass Fiber/Epoxy Composites

6. R. G. Jones, in High frequency dielectric measurement, eds. J. Chamberlain and G. W. Chantry, IPC Science and Technology Press Ltd, 1972. 


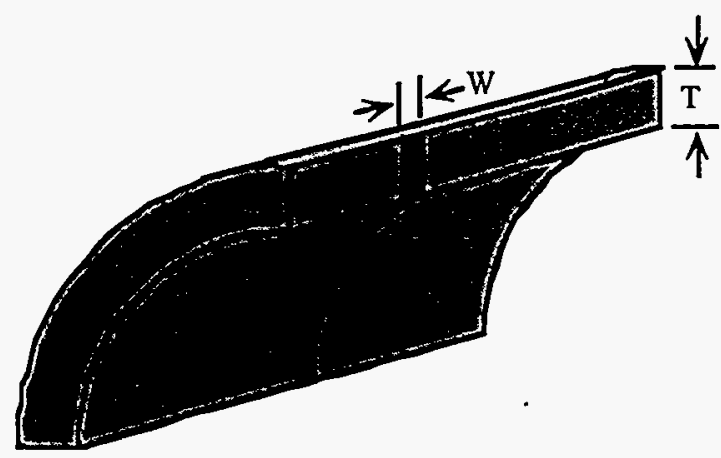

(a)

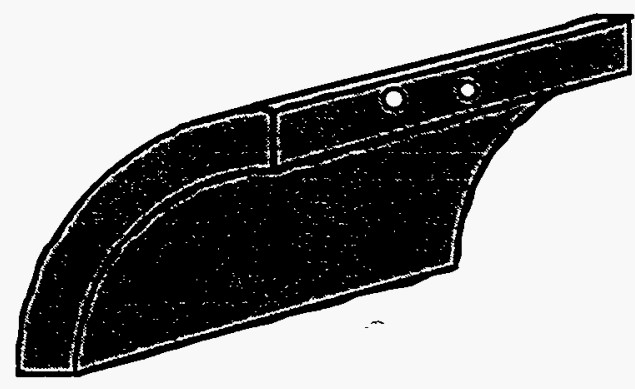

(b)

Figure 1. Geometry of $90^{\circ}$ sections of HDPE pipe samples showing (a) typical sample with butt-fused region indicated, and (b) two subsurface holes (artificial voids).

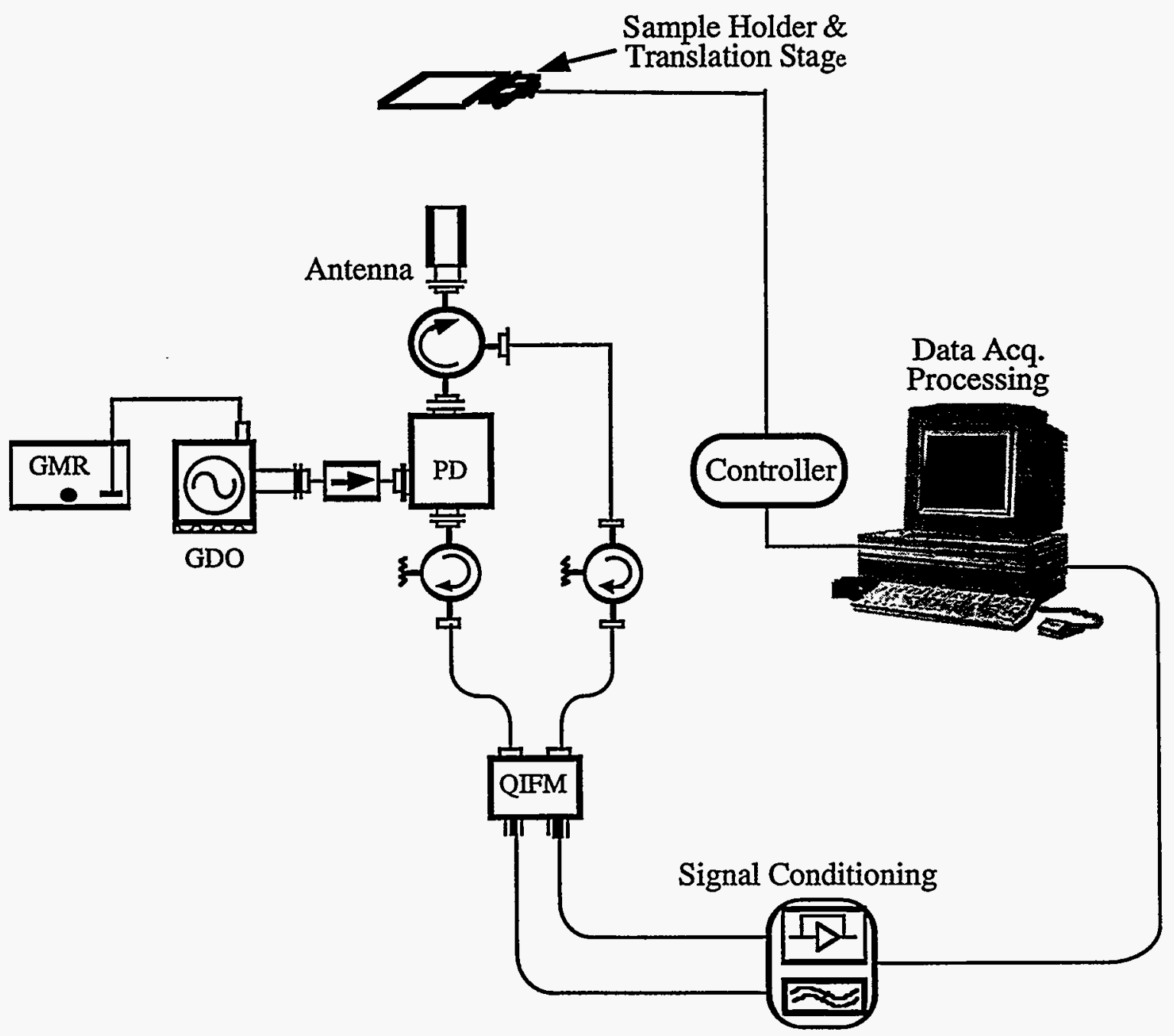

Figure 2. Block diagram of the monostatic millimeter wave (w-band) sensor for NDT of dielectric composite samples. 

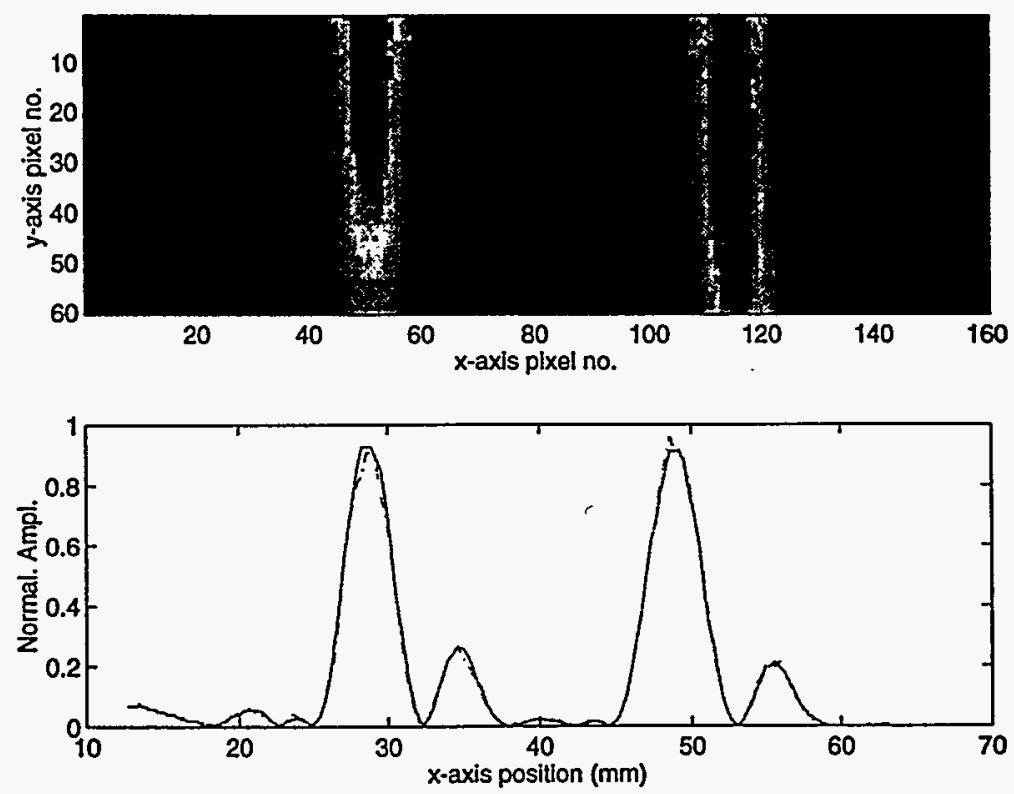

(a)
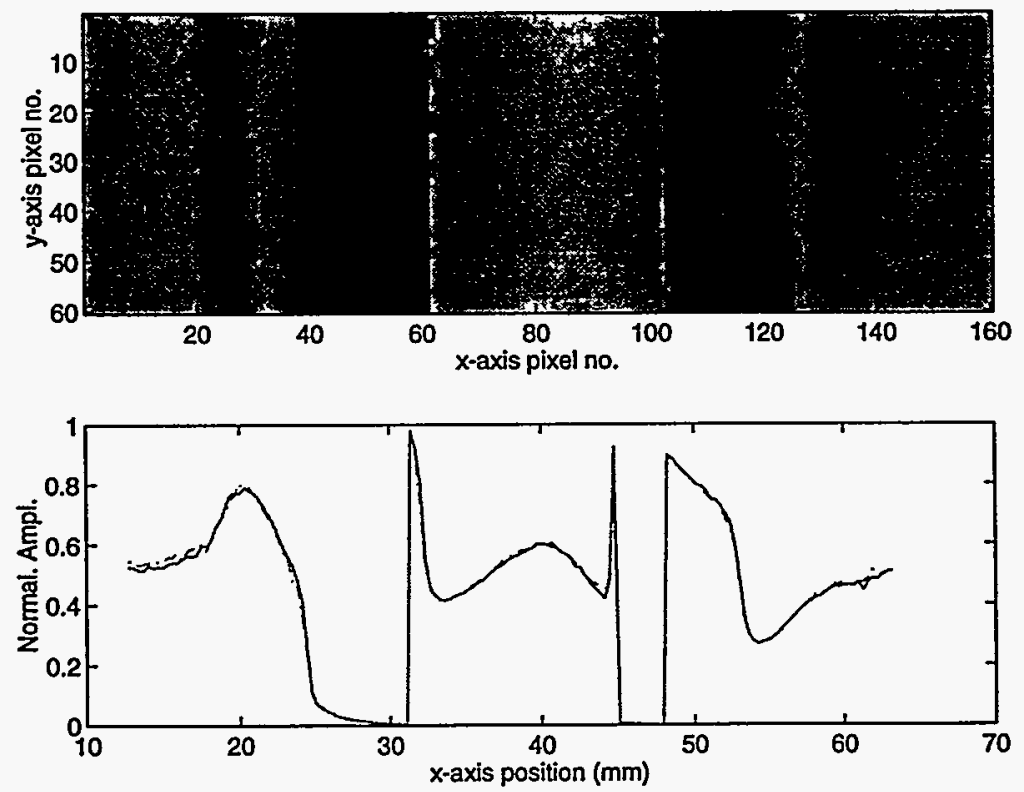

(b) 1

Figure 3. Measurements of normalized (a) amplitude, and (b) phase for the HDPE sample with two artificial subsurface voids. 

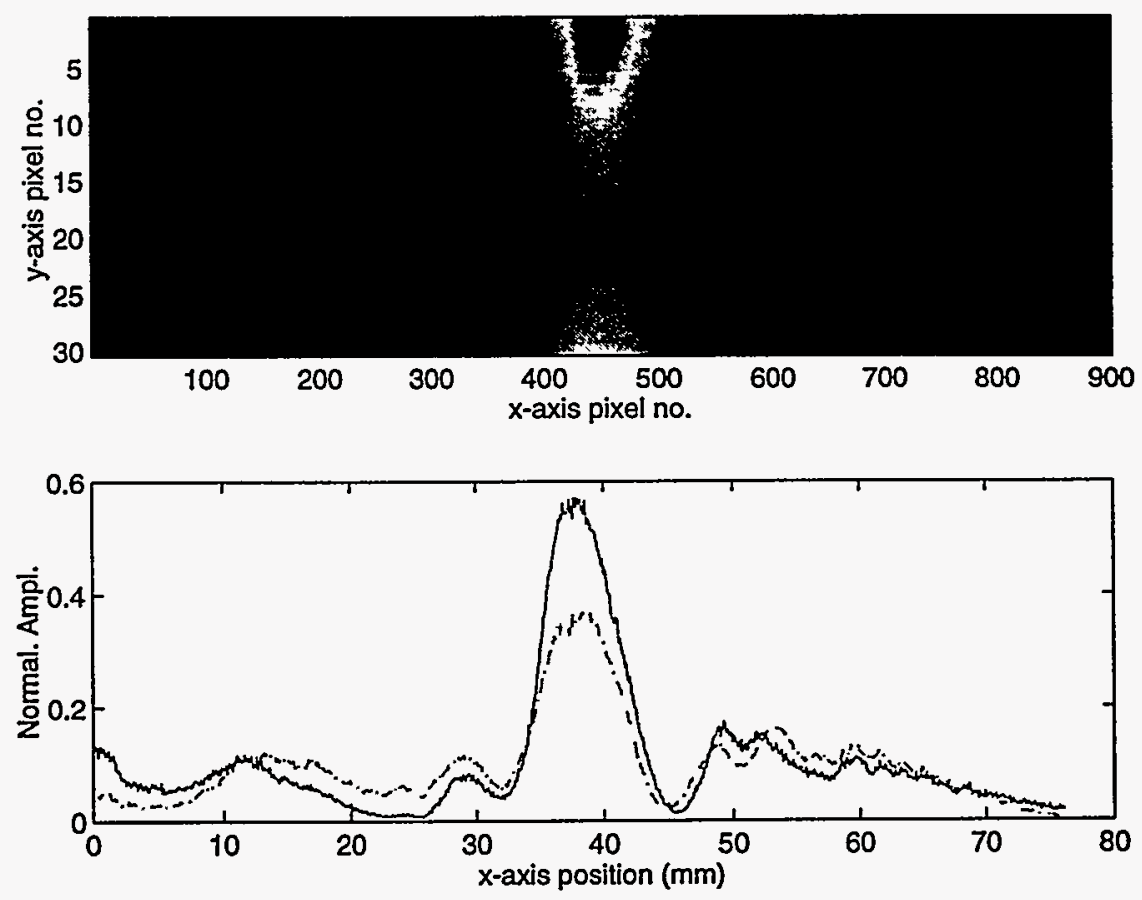

(a)
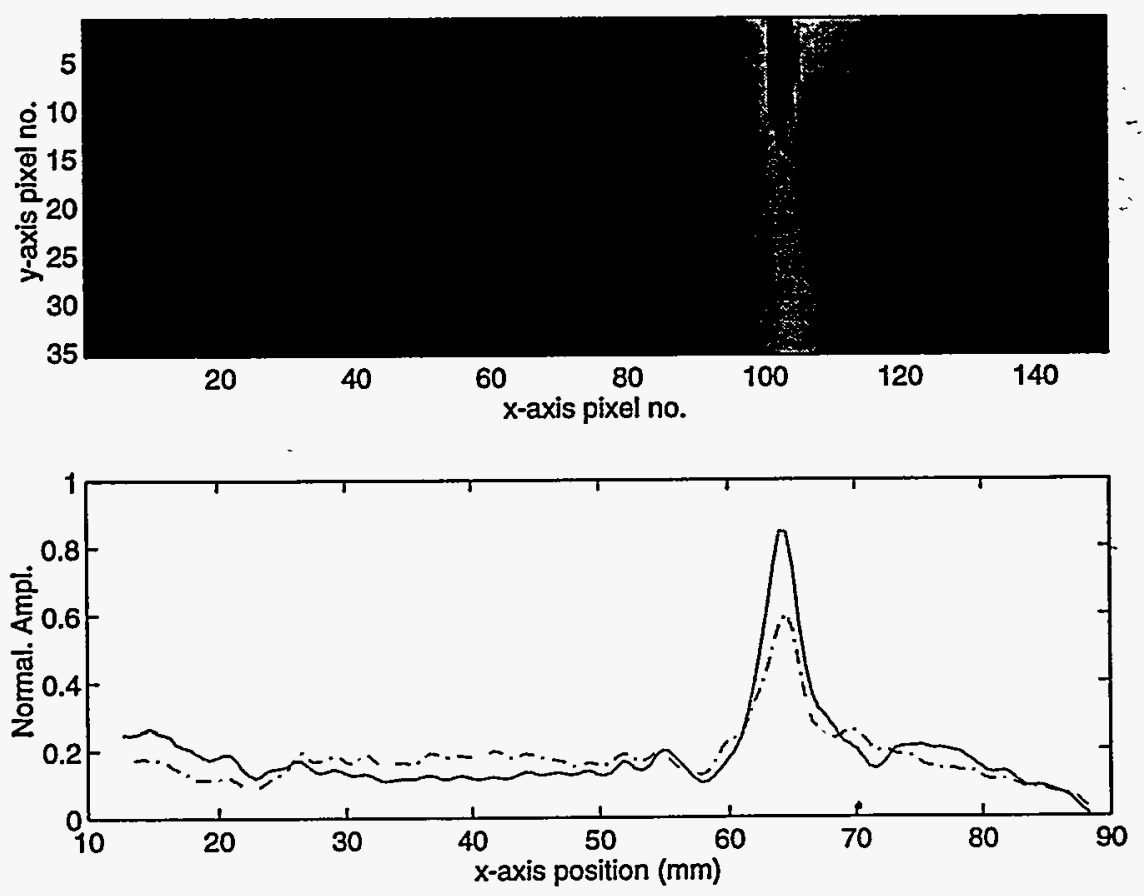

(b)

Figure 3. Measurements of normalized amplitude in (a) through-transmission, and (b) reflection modes for the HDPE sample with an acceptable bond quality. 

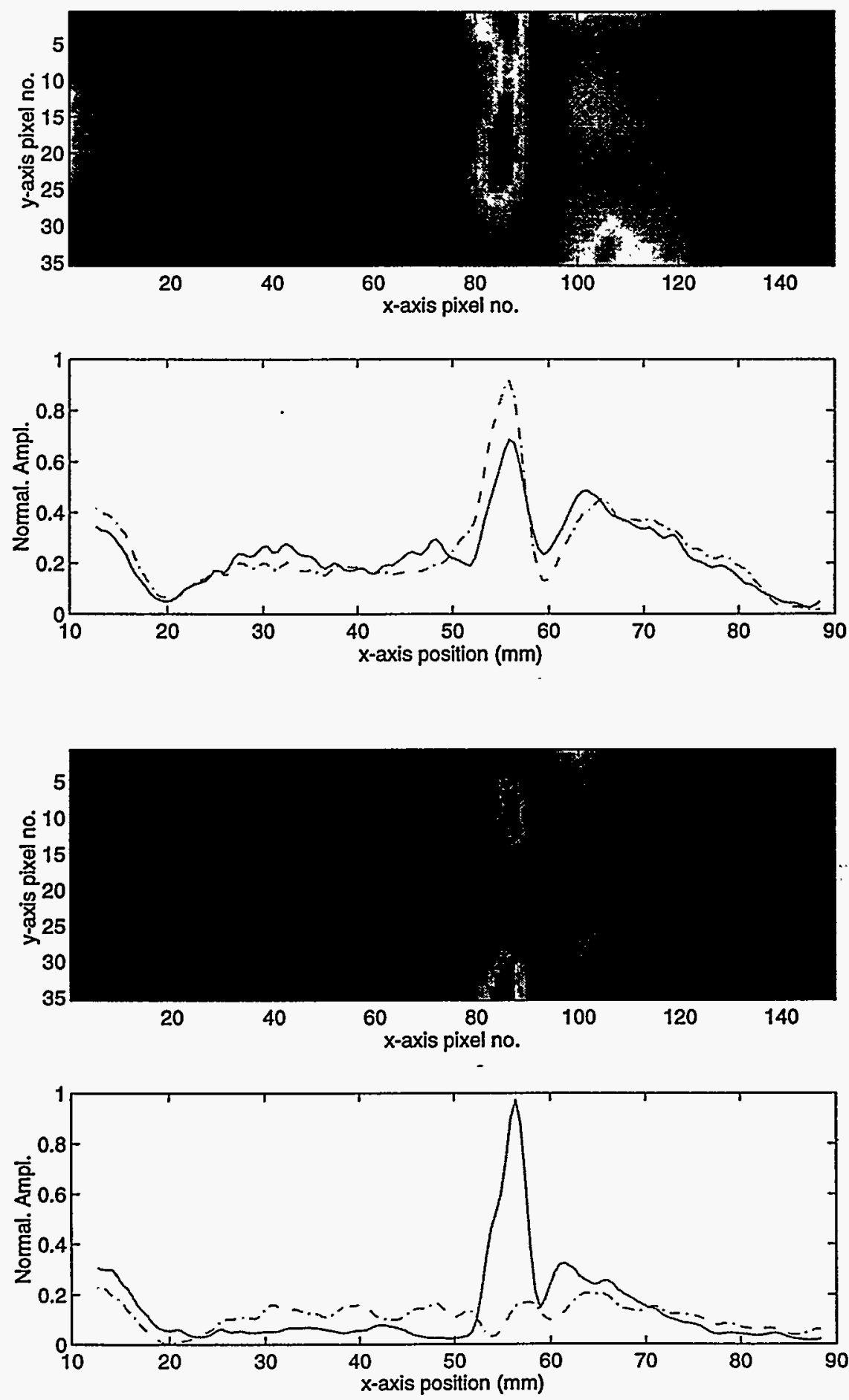

(b)

Figure 3. Measurements of normalized amplitude for two HDPE tube samples with unacceptable bond quality (defective joint). 